\title{
Analysis of used disinfectants and antiseptics correlated with the occurrence of nosocomial infections - Clinical hospital Stip, Republic of Macedonia in period of 2007 - 2011
}

\author{
Sofija Petkovska ${ }^{1}$, Biljana Gjorgjeska ${ }^{2}$ \\ Univesity Goce Delcev, Fakulty of medical sciences
}

\begin{abstract}
Intra-hospital or nosocomial hospital infections are caused by microorganisms acquired during the hospitalization of the patient, and clinically are manifested from 48 to 72 hours after admission at earliest. The procedures for disinfection and the type and quantity of disinfectants used are directly related to the effects. The control of intra-hospital infections is performed by intra-hospital infections Commission which is responsible for taking swabs of sediments and air for proving none/presence of bacteria, as well as taking measures if contamination occurs and timely detection of intra-hospital infections.

This research's aim is to review and select appropriate ways in order to prevent intra-hospital infections. Statistical processing of data received from Clinical Centre in Stip, Republic of Macedonia in the period 2009 to 2013 gives a complete insight into the connection between the use of disinfectants with occurrence and absence of intra-hospital infections. Prevention of intra-hospital infections is possible only by implementing standard processes and procedures that enable optimal use of properly selected disinfectants in all departments in hospitals. Special attention should be given to the procedures for preparing and delivering food to patients and the procedures for disinfection and control of space and food preparation, store and distribute food.
\end{abstract}

\section{INTRODUCTION}

Nosocomial infections represent worry in great proportions for both staff and patients. Therefore, they give great emphasis on proper prevention which includes primarily the optimal use of disinfectants and antiseptics, and regular microbiological testing and controls. Antiseptics and disinfectants are widely used in hospitals and other medical facilities in different topical application and hard surfaces. The composition of disinfectants into a wide variety of active chemical agents (biocides) applied over hundreds of years and according to the chemical composition represent alcohols, phenols, iodine and chlorine compounds. Most of these active substances show a broad spectrum of antimicrobial activity, but little is known about the mode of action of these agents compared with the action of antibiotics. In general, biocides have a broader spectrum of action than antibiotics. While antibiotics tend to target specific intracellular targets, biocides have different, multiple goals. The widespread use of these products raises doubts among many scientists and researchers to the development of antibiotic resistance, especially cross-resistance with the question whether resistance to antibiotics is caused by the use of antiseptics and disinfectants. [1]

Mechanical cleaning before application of disinfectants is essential. Mechanisms of antibacterial disinfectants are summarized in several large critical reports worldwide. For example, alcohols show rapid action and broad spectrum of antimicrobial activity through denaturation of proteins, but do not act sporicidal. Aldehydes act by linking the amino groups of proteins, RNA and DNA. Oxidizing agents such as peroxides and halogens oxidize proteins thiol groups while surface active agents mainly act on the cytoplasmic membrane of the bacterial cell or plasma membrane of the yeasts. Phenols generally destroy the membrane.

For the use of biocides as chemicals is important to note that many of these biocides can be used independently or in combination with various other products that differ significantly in their activity. Antimicrobial activity may be influenced by many factors that can arise from the formulation, the synergistic activity, temperature, dilution and evaporation. Biocide is a general term used to describe a chemical agent, usually with a broad spectrum of activity, which inactivates microorganisms. Biocidal activity is within the antimicrobial activity, but depending on the conditions you have and "The State" activity that is directed to agents that inhibit growth (bacteriostatic, fungistatic and sporostatic activity), and also "cidal" activity directed agents to completely destroy all microorganisms present (bactericidal, sporicidal, fungicidal).[2]

Regardless of the type of organism that is present there is always a common sequence of events. Previous interaction means disinfecting or antiseptic to the cell surface followed by penetration into the cell or simply target cell activity. The nature and composition of the surfaces vary from one cell to another. But external factors or environmental factors can also affect the activity of antiseptics and disinfectants. The 
interaction with the bacterial cell surface can have a significant impact on the sustainability of the effect of the used chemicals, but insignificant stake is the fact that most antimicrobial agents act intracellular.

The interior of the bacterial cell can thus have a significant impact on the general, overall durability of the bacterial cell or a different sensitivity to disinfectants and antiseptics, which is quite disappointing how little is known and there is evidence to the effect and impact of funds disinfectants and antiseptics to different types of bacterial cells. However, the potentiating of the action of certain disinfectants and antiseptics can be achieved by using different additives that significantly increase their potency.

\subsection{Hospital-acquired infection (nosocomial infection)}

A great number of studies around the world show and prove that hospital infections are a major cause of morbidity and mortality. High frequency of hospital infections is evidence of poor quality of health services and lead to unforeseen and unavoidable expenses. Many factors contribute to the incidence of hospital infections: hospitalized patients are often immuno-compromised. Often, subjected to invasive treatments and examinations and practical patient care in the hospital environment can facilitate the transmission of microorganisms among patients. The intensive use of antibiotics promotes the same resistant. Advances in the prevention of hospital infections is steadily increasing, and studies of the proper application and use of disinfectants, depending on their purpose and structure are constantly emerging. [3]

The incidence of nosocomial hospital infections is still conducted in 1966 a study on the occurrence of infection caused by the Staphylococcus Aureus. The research has been done on different types of staphylococci responsible for the occurrence of cross infections in large hospitals between 1961 and 1966. Research has shown that infections are caused by three different types of staphylococcal to later identify and prove new species resistant to antibiotics. Two main groups of staphylococci were isolated species responsible for most cases of cross-infection in two hospitals. Species resistant to antibiotics are proven epidemiological types. It was proved that the typical group which causes infection is the main cause of infections in patients with open wounds and surgical areas with skin ulceration. The correlation was established between species resistant to antibiotics and similar vines of the two different types of bacteria. This research has provided result in increased guidance for improving the control of the occurrence of infections in hospitals and taking appropriate measures to prevent further spread. [4]

National surveillance for infection control departments for coronary artery bypass grafting in Norway started operating in 2005. A study designed to measure and establish baseline incidence of the occurrence of infections in these departments, was conducted to describe the characteristics of patients, procedures and to identify possible risks of infection. [5]

Protection and prevention of nosocomial infections as patients and staff brings important for every healthcare institution. Study on integrated mechanism for protection of patients was conducted during 2001 and explains all procedures, methods, protocols and aspects for better patient care and also includes protection against hospital infections. The same study develops system with integrated mechanism, a scheme for patient protection and infection control staff deals with four main issues

- What are the requirements for the control of infection in terms of performance requirements of the patients

- What are the best ways to achieve these results?

- Who should be responsible for the results?

- Are there guidelines based on evidence that should be incorporated into protocols for protection [6]

In order to comprehensively monitoring hospital infections in health care, patients are asked to monitor the studies about the point of prevalence of hospital infections. Monitoring of point prevalence was first established in Canada in University Hospital to establish baseline data about the occurrence of hospital acquired infections. This approach attempts to overcome the multitude of barriers, to practice universal surveillance potential and to achieve quantitative estimate of the number of hospital infections that occur. The study indicates that a reasonable alternative to this method is the development of a method that will rely on the concentrated control of microbial cultures.[7]

A 2008 study suggests very few published reports on key focus of hospital teams of hospital infection control. Evidence from research suggests a multidisciplinary team based at the hospital, which should have a strategic approach and commitment to control hospital infections in all clinical areas. The structure and operation of teams includes supervision and differs from hospital to hospital from clinic to clinic depending on their needs. High quality and efficiency are crucial to reduce the risk of nosocomial infections, and as a result, and reduce mortality and morbidity in hospitals. [8]

The basic tool of a study indicates that the data collection is necessary and to be used in order to advance a sweeping operation to improve the performance of a health institution. Teams of professionals constantly have access to all data for the possible occurrence of hospital infections. 
By simply collecting, collating and analysing all available data can reach effective conclusions. A simple description of the data can lead to many important facts that will be helpful in providing better protection and guidance on the specific procedures for protection. The study indicates that the primary should beware teams professionals involved in the protection against infection.

- What data on the occurrence of hospital infections are routinely available daily

- Is this sufficient data can be gathered to describe the infection occurred during testing and epidemiological research

- How effective is the data used

- Is different, not daily presentation of the data will have a different effect

- What are the key priorities for the control of hospital infections in a healthcare institution and which data, methods and means of presenting the data would be best to improve the control of hospital infections [9]

The literature provides many examples and explanations for microbial resistance to disinfectants. This can be proved either by laboratory experiments using elevated levels of biocides to choose the most appropriate, depending on the bacterial population or by examining biocidal solutions the presence of resistant microbial strains. Gram-negative bacilli are the most common isolates from this type of evaluation biocidal activity. This may be due to a combination of factors including changes in the permeability of the outer membrane which in turn is due to the change in the diameter of the pores. [10]

Most disinfectants and antiseptics used in hospitals are prepared as solutions in hospital pharmacies from where they are distributed to all hospital departments. Research shows that contamination is possible during their manufacture. The level of contamination of some bacterial species ranges from 102 to 108 bacterial colonies formed per millilitre disinfectant / antiseptic to the possibility of achieving the infectious dose at the site of application. Epidemiological reports indicate many hospitals which often use contaminated disinfectants and antiseptics applied directly to the skin of patients, and are often used for decontaminations of instruments and diagnostic devices for treatment of patients. The data suggests many resistant bacteria isolated from disinfectants and antiseptics.[11].

\section{GOALS}

The purpose of this paper is to show the connection between the used disinfectants and antiseptics in the Clinical Centre - Stip for five years, from 2007 to 2011 and the possible occurrence of hospital infections.

\section{MATERIALS AND METHODS}

The data used for antiseptics and disinfectants are derived from

- Annual Evidence List of Clinical Centre - Stip. They are processed separately for each ward.

- Annual reports of the Centre for Public Health Stip - Epidemiologic Service.

The statistical analysis of the data analysed is the use of disinfectants and antiseptics annually each ward separately in Clinical Centre - Stip compared with the results of the microbiological analysis carried out in the Centre for Public Health - Stip. It is estimated the possible occurrence of hospital infections over a period of five years. The processed data provide the following results.

\section{RESULTS}

The total amount of the most commonly used antiseptics and disinfectants of all departments in the Clinical Hospital - Stip in 2007 and 2011 is shown in Table 1.

Table 1: Total amount of commonly used antiseptics and disinfectants of all departments in the Clinical Hospital - Stip in 2007 to 2011.

\begin{tabular}{|c|c|c|c|c|c|c|c|c|c|c|c|c|c|c|c|c|c|c|c|}
\hline & & & & & & & & & & & & & & & & & & & \\
\hline 2007 & 17 & 294 & 237 & 186 & 233 & 31 & 28,4 & 22 & 600 & & & 1025 & 0 & 0,5 & & 79 & & 6,6 & \\
\hline 2008 & 32 & 930 & 587 & 503 & 599 & 397 & 84 & 62 & & & 5 & 1650 & 0,5 & 20 & & 311 & & & \\
\hline 2009 & 22 & 377 & 264 & 268 & ol & 147 & 87,9 & 22 & 16800 & 61,5 & 180 & 840 & & & & & & & \\
\hline 2010 & 21 & 157 & 210 & 186 & 12,5 & 22 & 31,4 & 23 & 10800 & 150 & 132,5 & 0 & 38,5 & & 4.5 & & & & \\
\hline 2011 & 13 & 123 & 315 & 194 & 166 & 69 & 30,6 & 20 & 200 & 91,6 & & & 4 & 0,5 & & 4 & 12000 & & \\
\hline totol & 105 & 1881 & 1613 & 1337 & 1010,5 & 666 & 262,3 & 149 & 28890 & 303,1 & $|317,5|$ & 3515 & 57 & & 16,5 & 390 & 18930 & 48,6 & \\
\hline
\end{tabular}

Graph No. 1 - Consumption of commonly used antiseptics and disinfectants in liquid form during the years from 2007 to 2011 


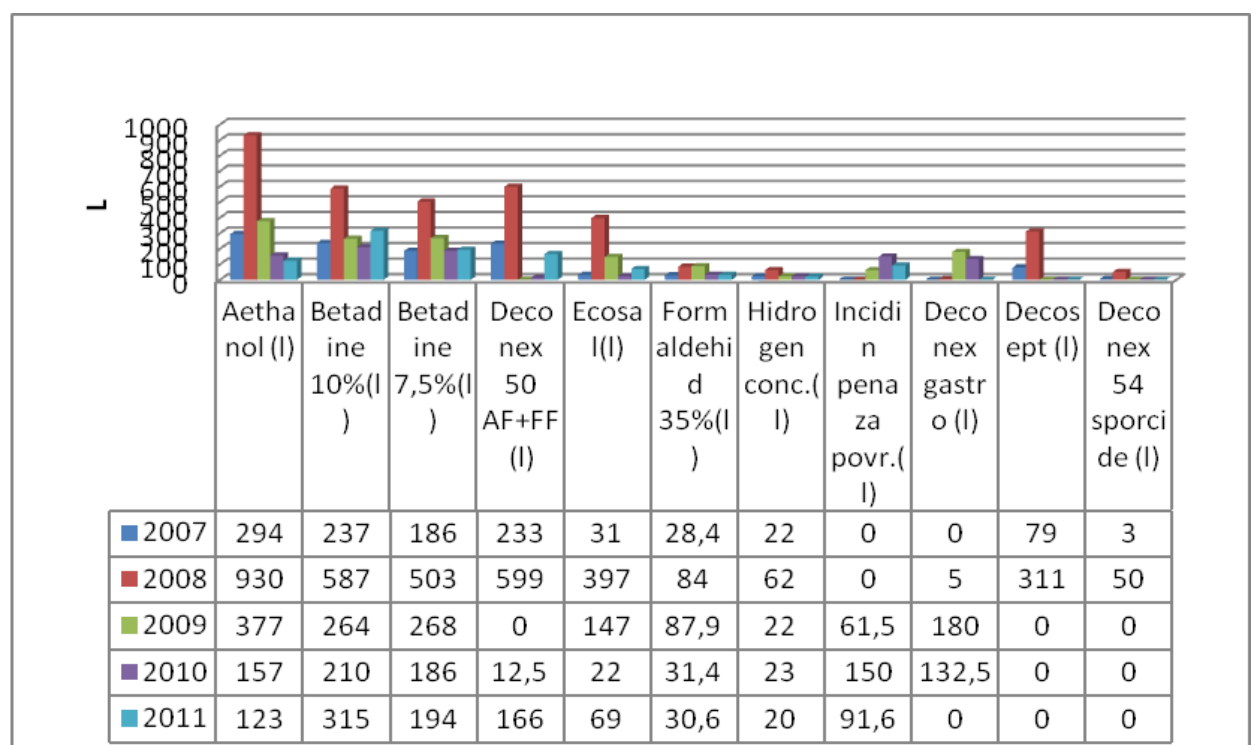

In the period from 2007 to 2011 used antiseptics and disinfectants in liquid form, in 2007 spent the greatest amount of Aethanol (294 liters), and the smallest amount Deconex 54 sporcide (3 liters). In 2008 spent the greatest amount of Aethanol (930 liters), and the smallest amount Deconex gastro (5 liters). In 2009 spent major amounts of Aethanol (377 liters), and the smallest amount Hidrogen conc. (22 liters). 2010 spent major amounts of Betadine 10\% (210 liters), and the smallest amount Deconex $50 \mathrm{AF}+\mathrm{FF}$ (12,5 liters). In 2011 spent major amounts of Betadine 10\% (315 liters), and the smallest amount Acidi Borici (13 liters).

Graph No. 2 - Consumption of commonly used antiseptics and disinfectants in solid form during the years from 2007 to 2011.

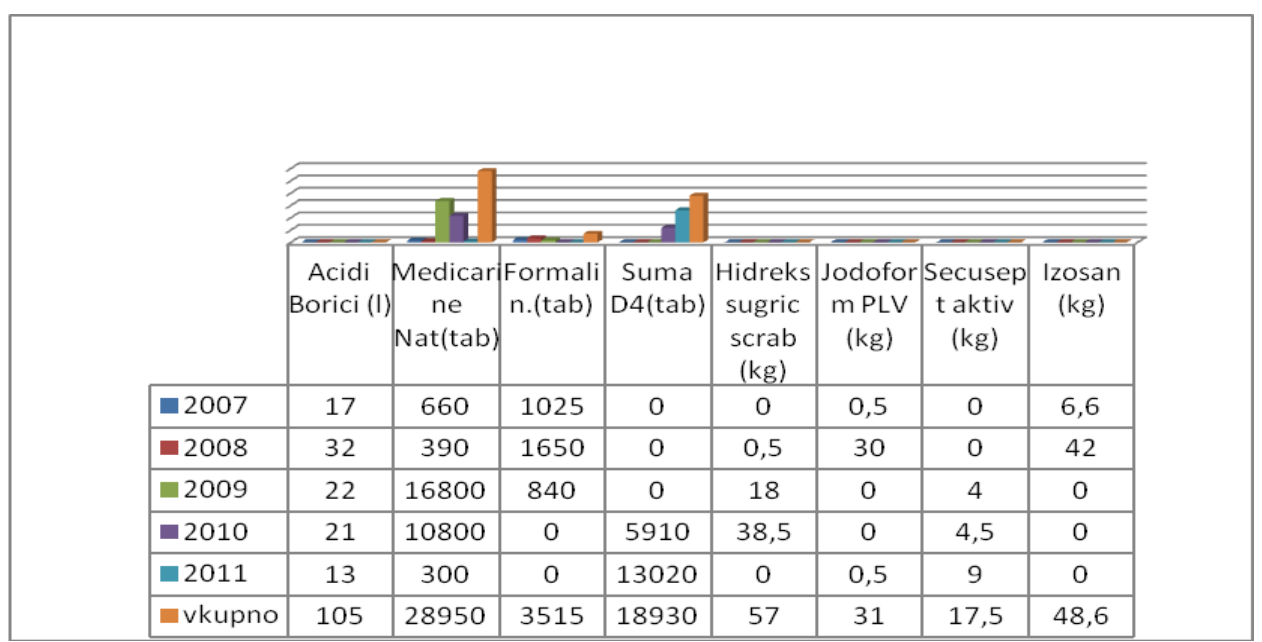

In the period from 2007 to 2011 of disinfectant and antiseptics used in the solid state, in 2007 spent the greatest amount of Formaldechide tablets (1025), and the smallest amount of Jodofrm PLV (0,5 kg). In 2008 spent major amounts of Formaldechide tablets (1650), and the smallest amount Hidreks surgic scrab (0,5 kg). In 2009 spent major amounts of Medicarine Nat. (16800 tablets), and the lowest amount Sekusept aktiv (4 kg). In 2010 spent major amounts of Medicarine Nat (10800 tableti), and the smallest amount Sekusept aktiv (4,5 kg). In 2011 spent major amounts of Suma D4 (13020 tableti), and the smallest amount Jodoform PLV (0,5kg)

The total amount of commonly used antiseptics and disinfectants in hospital departments in Clinical hospital - Stip in the period from 2007 to 2011 is shown below.

Graph No. 3 - Quantities of antiseptics and disinfectant spent in Gynaecology department in the Clinical Hospital - Stip in period of 2007 and 2011. 


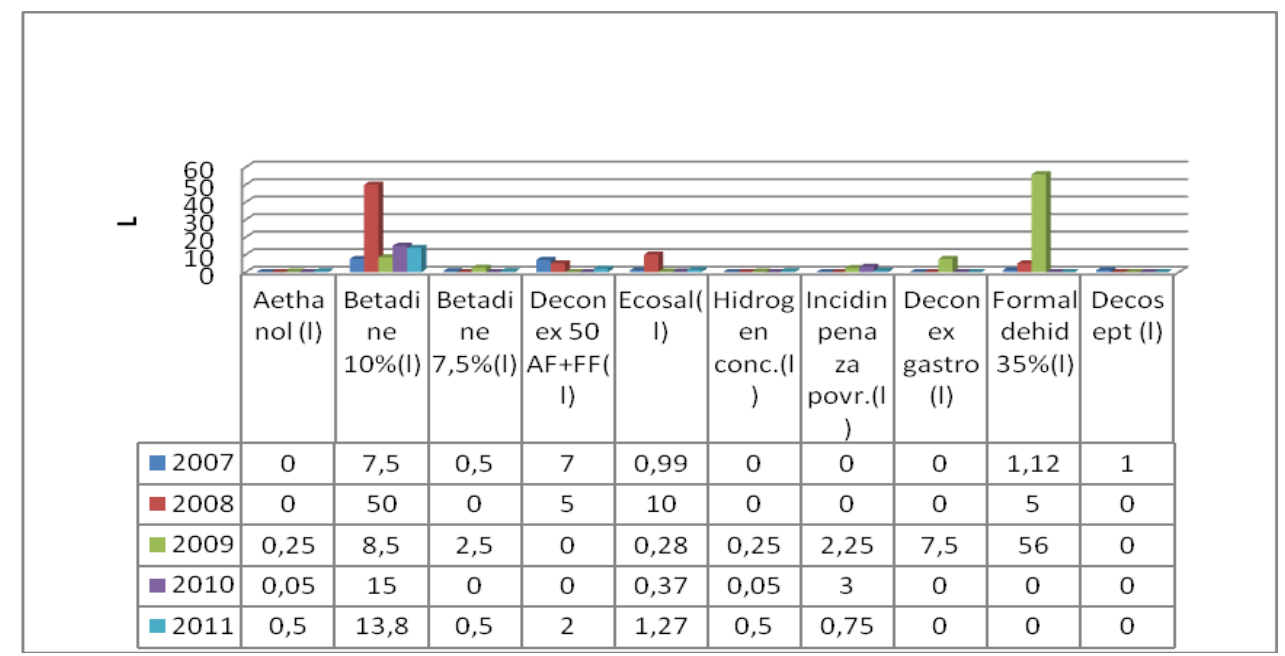

Gynecology department in the period from 2007 to 2011 spent major amounts of antiseptics and disinfectants in liquid form: Betadine 10\% (total 94.8 liters), and the smallest amount of Decosept (1 liter). 2007 consumed the greatest amount of Betadine 10\% (7.5 liters), and the lowest amount of Betadine 7,5\% (0,5 liters) while Aethanol conc., Hidrogen conc., Incidin foam. and Deconex gastro were not used. 2008 spent major amounts of Betadine 10\% (50 liters), and the lowest amount of Deconex $50 \mathrm{AF}+\mathrm{FF}$ (5 liters), Formaldehid $35 \%$ (5 liters), while Aethanol conc., Betadine 7,5\%, Hidrogen conc. Incidin foam., Deconex gastro and Decosept are not used at all. In 2009 are spent most of Betadine 10\% (8.5 liters), the lowest spent amount is Aethanol conc. (0.25 liters) and Hidrogen conc. (0.25 liters) while Deconex $50 \mathrm{AF}+\mathrm{FF}$ and Decosept are not uset at all. In 2010 spent the least amount of Aethanol (0,05 liters) and Hidrogen conc. (0.05 liters), while Betadine 7,5\%, Deconex 50 AF + FF, Deconex gastro, Formaldehid 35\% and Decosept are not used at all. In 2011 spent major amounts of Betadine 10\% (13.8 liters), and minor amounts of Aethanol conc. (0.5 liters), Betadine 7,5\% (0,5 liters) and Hidrogen conc. (0.5 liters) while Deconex gastro, Formaldehid 35\% Decosept are not used

Graph No. 4 - Quantities of antiseptics and disinfectant spent in Intensive care in the Clinical Hospital - Stip in period of 2007 and 2011

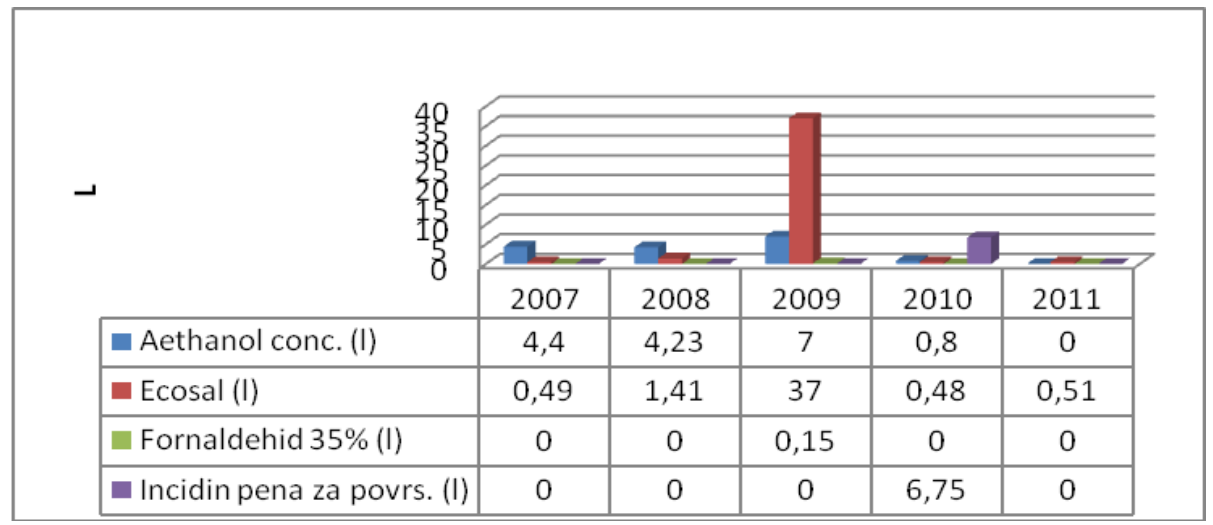

The Intensive Care unit spent largest amounts of Ecosal (total of 39.89 liters), and the smallest amount of Formaldehide 35\% (0.15 liters). In 2007 the largest amount is spent of Aethanol conc (4,4 liters), and the lowest Ecosal (0,49 liters). Formaldehide 35\%, Incidin foam are not used. In 2008 the largest amount is spent of Aethanol conc. (4,23 liters), and the lowest Ecosal (1,41 liter). Formaldehide 35\%, Incidin foam are not used. In 2009 consumed the greatest amount of Ecosal (37 liters) and and the lowest Formaldehide 355 (0.15 liters). In 2011 was used only Ecosal and spent total 0.51 liters.

Graph No. 5 - Quantities of antiseptics and disinfectant spent in Internal medical department in the Clinical Hospital - Stip in period of 2007 and 2011. 


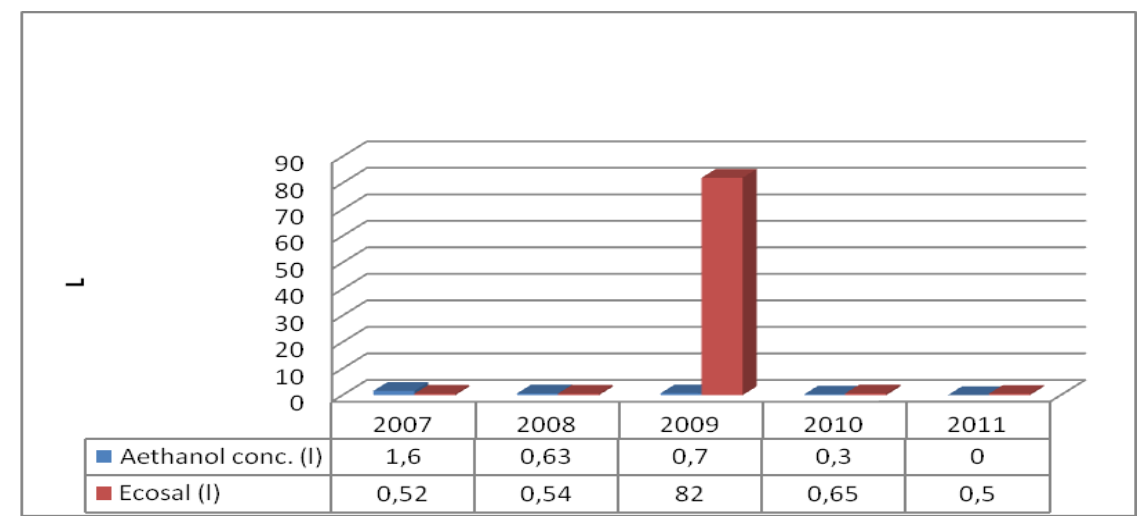

In the Internal medical department used antiseptics and disinfectants are only Aethanol conc. and Ecosal. In largest quantities is used Ecosal (total 148.5 liters) and smaller Aethanol conc. (3.23 liters). In 2007 and 2008 a greater amount is spent of Aethanol conc, in 2009, 2010 and 2011 is more used Ecosal.

Graph No. 6 - Quantities of antiseptics and disinfectant spent in Urology department in the Clinical Hospital Stip in period of 2007 and 2011.

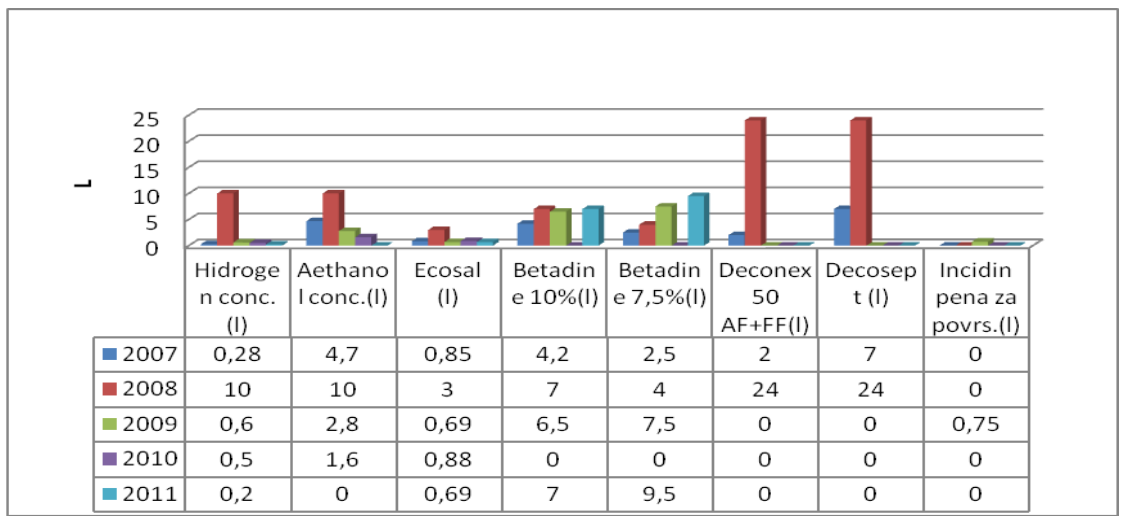

The Urology department spent major amounts of Decosept (31 liter), and the smallest amount of Incidin foam (total of 0.75 liters). In 2007 spent major amounts of Decosept ( 7 liters), and the smallest amount of Hidrogen conc. (0,28 liters), while Incidin foam is not used. In 2008 spent major amounts of Deconex $50 \mathrm{AF}$ + FF and Decosept 24 liters, the smallest amount of Ecosal (3 liters), while Incidin foam is not used. In 2009 spent major amounts of Betadine 7,5\% (7,5 liters), the smallest amount of Hidrogen conc. (0.6 liters) while Deconex $50 \mathrm{AF}+\mathrm{FF}$ and Decosept are not used. In 2010 spent major amounts of Aethanol conc. (1.6 liters), the smallest amount of Hidrogen conc. (0,5 arch), and Betadine 10\%, Betadine 7,5\%, Decosept, Deconex $50 \mathrm{AF}+$ FF and Incidin foam are not used. In 2011 spent major amounts of Betadine 7,5\%, the lowest amount of Hidrogen conc. (0.2 liters) while Aethanol, Deconex $50 \mathrm{AF}+$ FF, Decosept and Incidin foam are not used.

Graph No. 7 - Quantities of antiseptics and disinfectant spent in Otorhinolaryngology department in the Clinical Hospital - Stip in period of 2007 and 2011.

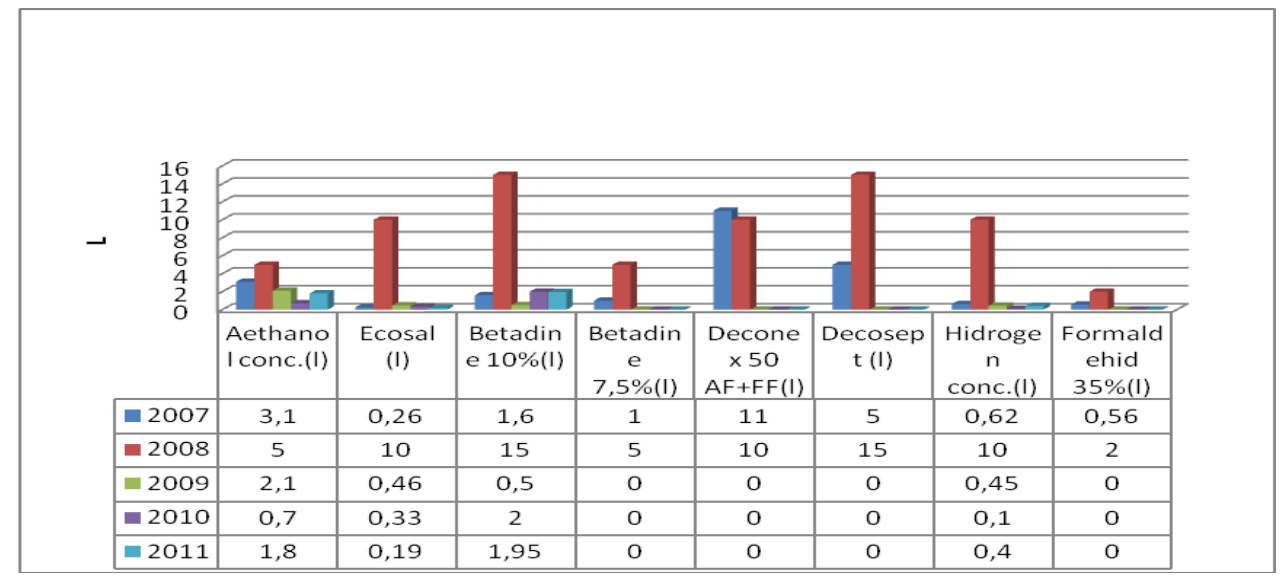


The otorhinolaryngology department consumed largest amounts of Deconex $50 \mathrm{AF}+\mathrm{FF}$ (21 liter), and the lowest amount of Formaldehide 35\% (total of 2.56 liters). In 2007 spent major amounts of Deconex $50 \mathrm{AF}+$ FF (11 liters), and the smallest amount Ecosal (0,26 liters). 2008 spent major amounts of Betadine and 10\% Decosept 15 liters, and the smallest amount Formaldehid 35\% (2 liters). In 2009 spent major amounts of Aethanol conc. (2,1 liter), and the smallest amount of Hidrogen conc. (0,45 liters), while Betadine 7,5\%, Deconex $50 \mathrm{AF}+\mathrm{FF}$, Decosept and Formaldehide $35 \%$ are not used. 2010 spent major amounts of Betadine 10\% (2 1), the lowest amount of Hidrogen conc. (0,1 liter), and Betadine 7,5\%, Deconex $50 \mathrm{AF}+\mathrm{FF}$, Decosept Formaldehid and 35\% are not used. In 2011 spent major amounts of Betadine 10\% (1.95 liters), the smallest amount of Hidrogen conc. (0,4 liters), while Betadine 7,5\%, Deconex $50 \mathrm{AF}+\mathrm{FF}$, Decosept Formaldehid and $35 \%$ are not are used.

The results of microbiological tests on swabs taken in Clinical Hospital Stip implemented at the Center for Public Health is shown as a percentage of contaminated and uncontaminated materials by departments and years.

Table No. 2 - Examined swabs in Clinical Hospital Stip in 2007

\begin{tabular}{|c|c|c|}
\hline Department & $\begin{array}{c}\text { Uncontaminated } \\
\text { materials \% }\end{array}$ & $\begin{array}{c}\text { Contaminated } \\
\text { materials \% }\end{array}$ \\
\hline $\begin{array}{c}\text { Intensive care } \\
\text { unit }\end{array}$ & $33 \%$ & $77 \%$ \\
\hline Gynecology dep. & $87,50 \%$ & $12,50 \%$ \\
\hline Surgery dep & $66,60 \%$ & $33,40 \%$ \\
\hline Pediatrics & $36,30 \%$ & $63,60 \%$ \\
\hline Dep. for dialysis & $100 \%$ & $0,00 \%$ \\
\hline Obstetrics dep. & $100 \%$ & $0,00 \%$ \\
\hline Orthopaedic dep. & $23,50 \%$ & $76,50 \%$ \\
\hline $\begin{array}{c}\text { Kitchen and } \\
\text { laundry }\end{array}$ & $37,50 \%$ & $62,50 \%$ \\
\hline
\end{tabular}

Graph No. 8 - Graphic display of swabs examined in Clinical Hospital Stip in 2007

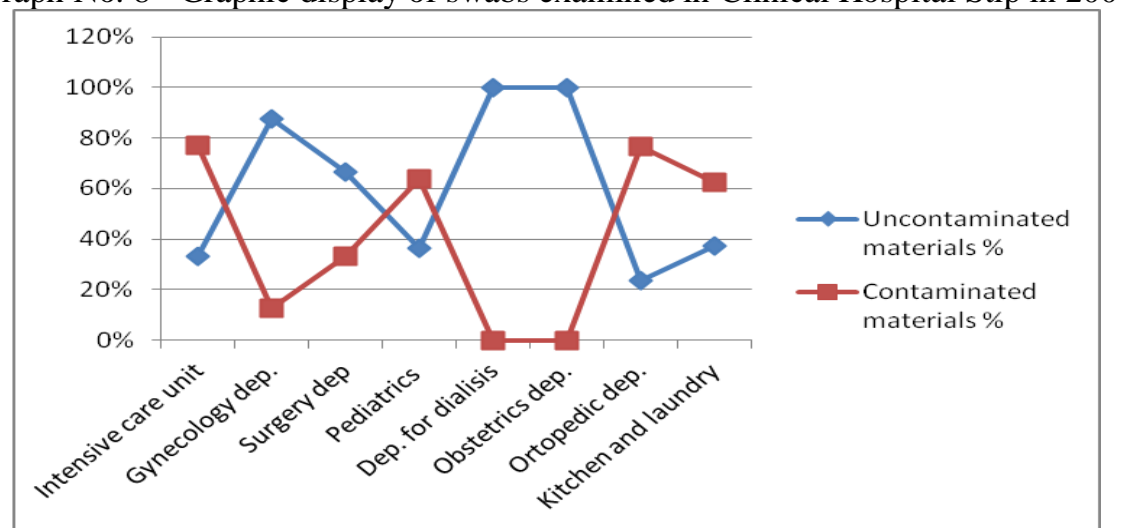

During the 2007 Center for Public Health has conducted 77 hygiene-epidemiological insights in several offices in Clinical Hospital Stip and other public and private health organizations in areas where is the greatest opportunity for the emergence and spread of hospital infections. The largest proportions of contaminated swabs were examined orthopaedic department where the percentage reaches $76.50 \%$ in one year. $100 \%$ uncontaminated material has been tested and proven on dialysis departments and obstetric unit.

Table No. 3 - Examined swabs in Clinical Hospital Stip in 2008.

\begin{tabular}{|c|c|c|}
\hline Department & $\begin{array}{c}\text { Uncontaminated } \\
\text { materials \% }\end{array}$ & $\begin{array}{c}\text { Contaminated } \\
\text { materials \% }\end{array}$ \\
\hline Gynecology dep. & $84,30 \%$ & $15,70 \%$ \\
\hline Surgery dep & $78,70 \%$ & $21,30 \%$ \\
\hline Orthopaedic dep. & $77 \%$ & $23 \%$ \\
\hline Anesthesiology dep & $50,90 \%$ & $49,10 \%$ \\
\hline Dep. for dialysis & $88,80 \%$ & $11,20 \%$ \\
\hline Pediatrics & $74,50 \%$ & $25,50 \%$ \\
\hline Other & $89,80 \%$ & $10,20 \%$ \\
\hline
\end{tabular}


Graph No. 9 - Graphic display of swabs examined in Clinical Hospital Stip in 2008

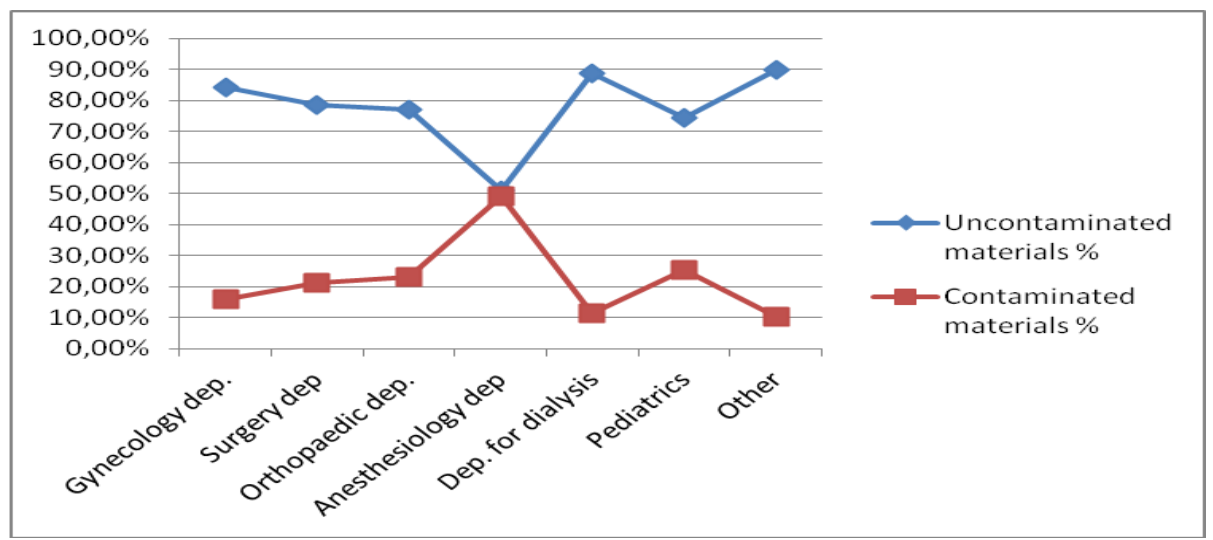

During the 2008 Center for Public Health Stip performed 36 hygiene-epidemiological insights in several offices in Clinical Hospital Stip and other public and private health organizations in areas where are the greatest opportunity for the emergence and spread of hospital infections. Total examined materials are 570 and 37 were spurious according to test for correctness of sterilization. Of these 480 are sterile, and in 90 of them were found present bacteria. In fact $15.7 \%$ of the materials are contaminated with bacteria. The largest percentages of swabs were contaminated at department of Anesthesiology $49.1 \%$, and the lowest percentage of dialysis $11.2 \%$.

Table No. 4 - Examined swabs in Clinical Hospital Stip in 2009

\begin{tabular}{|l|c|c|}
\hline \multicolumn{1}{|c|}{ Department } & $\begin{array}{c}\text { Uncontaminated } \\
\text { materials } \%\end{array}$ & $\begin{array}{c}\text { Contaminated } \\
\text { materials \% }\end{array}$ \\
\hline Gynecology dep. & $63 \%$ & $37 \%$ \\
\hline Surgery dep & $72,50 \%$ & $27,50 \%$ \\
\hline Orthopaedic dep. & $59,50 \%$ & $40,50 \%$ \\
\hline Anesthesiology dep & $72,90 \%$ & $27,10 \%$ \\
\hline Dep. for dialysis & $73,60 \%$ & $26,40 \%$ \\
\hline Pediatrics & $72,50 \%$ & $27,50 \%$ \\
\hline Other & $14,80 \%$ & $85,20 \%$ \\
\hline
\end{tabular}

Graph No. 10 - Graphic display of swabs examined in Clinical Hospital Stip in 2009

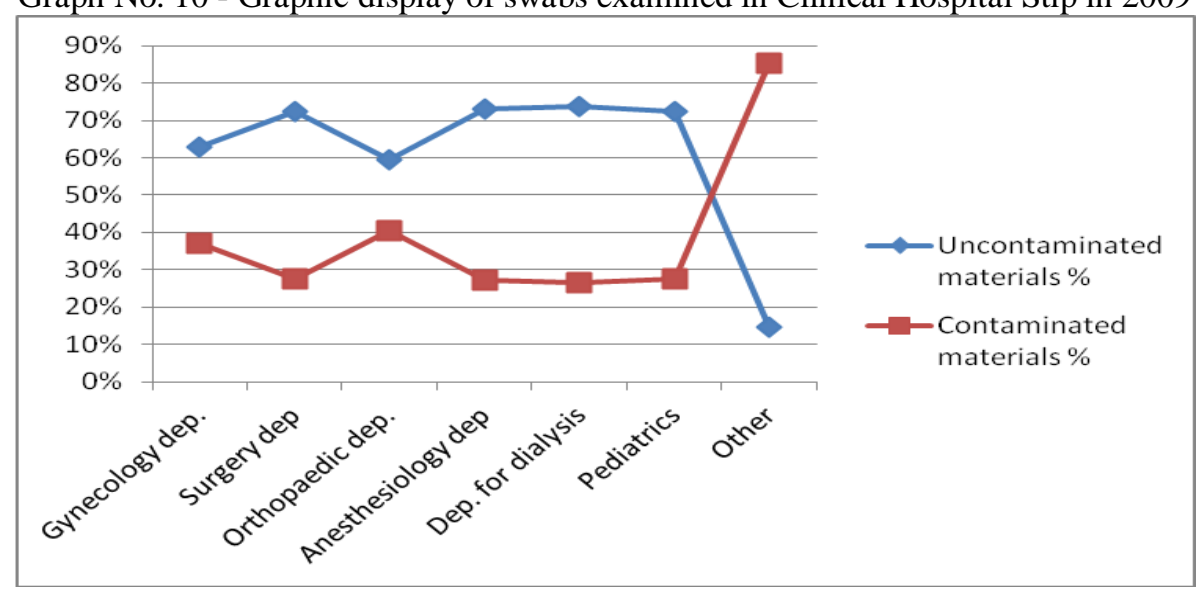

In 2009, were performed 34 hygiene-epidemiological insights in several offices in Clinical Hospital Stip and other public and private health organizations in the areas where are the greatest opportunity for emergence and spread of hospital infections. Once a month were taken materials for microbiological examinations (sediment air, swabs of surfaces and instruments and testing the accuracy of sterilization). Total surveyed 376 materials and 16 spores. 244 of this were sterile, and in 99 were found present bacteria. In fact $26.3 \%$ of the materials are contaminated with bakteria. largest percentages of swabs were recorded at the Department of Orthopaedics $40.5 \%$ and $26.4 \%$ at department for dialysis 
Table No. 5 - Examined swabs in Clinical Hospital Stip in 2010

\begin{tabular}{|l|c|c|}
\hline \multicolumn{1}{|c|}{ Department } & $\begin{array}{c}\text { Uncontaminated } \\
\text { materials \% }\end{array}$ & $\begin{array}{c}\text { Contaminated } \\
\text { materials \% }\end{array}$ \\
\hline Gynecology dep. & $71,80 \%$ & $28,20 \%$ \\
\hline Surgery dep & $60 \%$ & $40 \%$ \\
\hline Orthopaedic dep. & $75,40 \%$ & $24,60 \%$ \\
\hline Anesthesiology dep & $64,90 \%$ & $35,10 \%$ \\
\hline Dep. for dialysis & $54,90 \%$ & $45,10 \%$ \\
\hline Pediatrics & $66,20 \%$ & $33,80 \%$ \\
\hline Dep. for infectious diseases & $57,10 \%$ & $42,90 \%$ \\
\hline Ophthalmology dep. & $80 \%$ & $20 \%$ \\
\hline other & $75 \%$ & $25 \%$ \\
\hline
\end{tabular}

Graph No. 11 - Graphic display of swabs examined in Clinical Hospital Stip in 20010

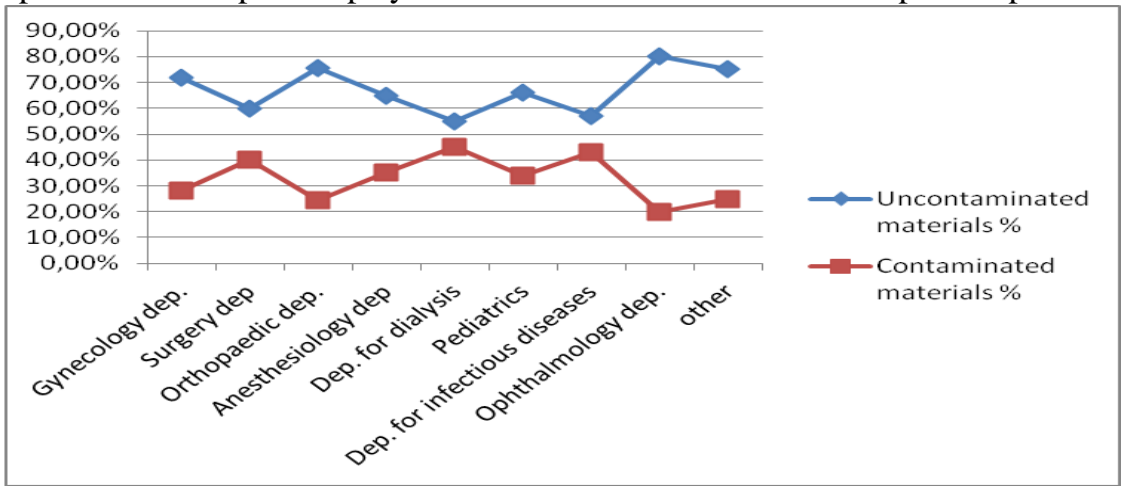

In 2010 epidemiological service of the Center for Public Health conducted 49 hygiene-epidemiological insights in Clinical hospital Stip. Total 604 materijals were examined. 436 of these were sterile and at 168 were found present bacteria. In fact $27.8 \%$ of the materials are contaminated with bacteria. The highest level of contamination was found at department for dialysis $45.1 \%$ and the ophthalmology department with $20 \%$. From hospital sterilization area were taken 24 spores and all were negative.

Table No. 6 - Examined swabs in Clinical Hospital Stip in 2011

\begin{tabular}{|l|c|c|}
\hline \multicolumn{1}{|c|}{ Department } & $\begin{array}{c}\text { Uncontaminated } \\
\text { materials \% }\end{array}$ & $\begin{array}{c}\text { Contaminated } \\
\text { materials \% }\end{array}$ \\
\hline Gynecology dep. & $77,70 \%$ & $22,30 \%$ \\
\hline Surgery dep & $61,20 \%$ & $38,80 \%$ \\
\hline Orthopaedic dep. & $64,70 \%$ & $35,30 \%$ \\
\hline Anesthesiology dep & $65,50 \%$ & $34,50 \%$ \\
\hline Dep. for dialysis & $83 \%$ & $17 \%$ \\
\hline Pediatrics & $74,30 \%$ & $25,70 \%$ \\
\hline Ophthalmology dep. & $80 \%$ & $20 \%$ \\
\hline other & $86,60 \%$ & $13,40 \%$ \\
\hline
\end{tabular}

Graph No. 12 - Graphic display of swabs examined in Clinical Hospital Stip in 2011

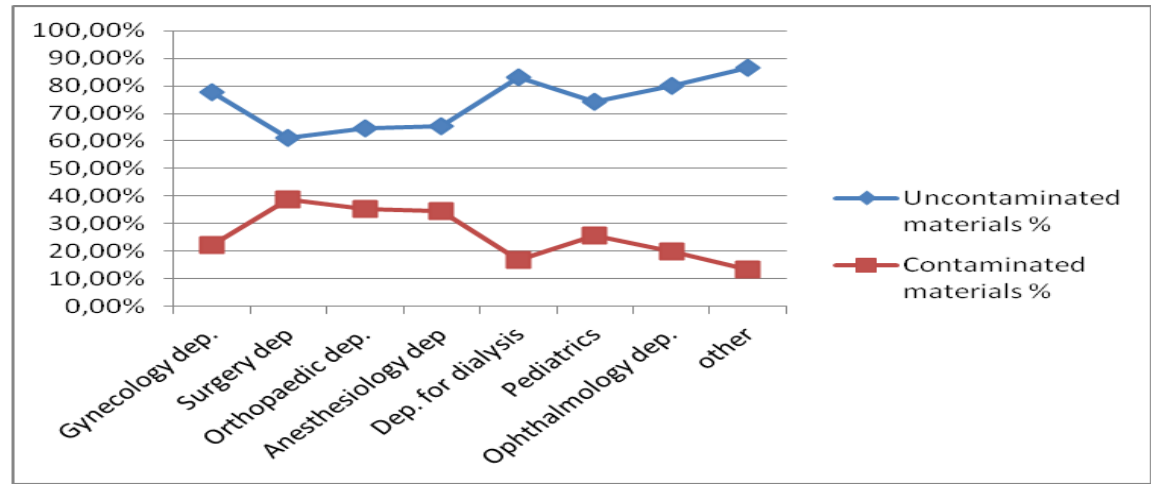


In 2011 epidemiological service of the Center for Public Health Stip perform 58 hygieneepidemiological insights in Clinical Hospital Stip in areas where is the greatest opportunity for emergence and spread of hospital infections.. During this year were examined total 587 materials. 462 of these were sterile and at 125 were found present bacteria. In fact $21.2 \%$ of the materials are contaminated with bacteria. The greatest percentage of contamination was found at surgery department $38.8 \%$ and $17 \%$ department for dialysis. From hospital pharmacy were taken seven samples of distilled water. All samples were without bacterial contamination.

\section{CONCLUSIONS}

In relation to Article 49 of the Law on protection of the population from infectious diseases Official. Gazette No. 66 of 01.10 .2004 and the Rulebook on the criteria for the prevention and elimination of intrahospital infections Official Gazette of RM No. 25 of 20.02.2008, and in order to prevent and eliminate intrahospital infections, shorter hospitalization and reducing of the cost of treating inpatients, adopted a Programme for the Prevention and suppression of intra-hospital infections, which is led by the Clinical hospital "Stip. Intrahospital infections represent a socio-economic problem. As a complication of the underlying disease, the number of hospital days, an average of $4-57 \%$, thus making a negative impact on the financial effects. The cost of hospital costs for additional antibiotic and other therapy, used to treat patients for the occurrence of hospital infections, can be increased by $3-42 \%$, depending on the type of infection. Proper use of disinfectants and antiseptics generally gives a good picture of the functioning of the health institution. Regular audits, managing them and cooperation with the Centre for Public Health enables maintaining hospital permissible limits for operation.

\section{REFERENCES}

[1]. Dr. Stefan Gartiser, Ismene Jäger, Efficiency and practicability of risk mitigation measures for biocidal products with focus on disinfectants, ENVIRONMENTAL RESEARCH OF THE FEDERAL MINISTRY OF THE ENVIRONMENT, NATURE CONSERVATION AND NUCLEAR SAFETY, pp 17

[2]. Gerald McDonnell, A. Denver Russell, Antiseptics and Disinfectants: Activity, Action, and Resistance, Clin. Microbiol. Rev. January 1999 vol. 12 no.1

[3]. Prevention of hospital-acquired infections, A practical guide, 2nd edition, 2002, World Health Organization, Department of Communicable Disease, Surveillance and Response

[4]. I. B. R. DUNCAN, M.D., F.R.C.P. [C], M.C.Path., London, Ont. And R. D. COMTOIS, M.Sc.,f Ottawa, Ont. Hospital Infections Caused by a Group of Recently Recognized Strains of Staphylococcus Aureus, THE CANADIAN MEDICAL ASSOCIATION, Le JOURNAL de L`ASSOCIATON MEDICALE CANADIENNE, APRIL 23, 1966 . VOL. 94, NO 17

[5]. Thale Cathrine Berg, Knut E. Kjørstad, Per Espen Akselsen, Bjørn Edvard Seim, Hege Line Løwer, Maryann Nesset Stenvik, Nina Kristine Sorknes, Hanne-Merete Eriksen, National surveillance of surgical site infections after coronary artery bypass grafting in Norway: incidence and risk factors, Oxford Journals, Medicine \& Health, European Journal Cardio-Thoracic Surgery, Volume 40, Issue 6, Pp. 1291-1297

[6]. Mary Henry and Margaret Brown, Using integrated care pathways to improve patient care, British Journal of Infection Control JUNE 2001 VOL. 2 NO.2, pp 20

[7]. Subhash C. Arya, Nirmala Agarwal and Shekhar Agarwal, Hospital acquired infection- point prevalence or culture-based surveillance? British Journal of Infection Control, VOL. 9 NO. 2 MARCH 2008, pp 23

[8]. C. Barrett, D. Hilder and J. Prieto, Infection control team workforce project, British Journal of Infection Control, 2008 9: 23, VOL. 9 NO. 4 JULY 2008, pp 26

[9]. Evonne Curran and Jennie Wilson, Using data effectively to prevent and control infection, British Journal of Infection Control 2008 9: 26, MAY 2008 VOL. 9 NO. 3, pp 31

[10]. Scott V.W. Sutton, PH.D, Disinfectant Rotation - A Microbiologist's View, Controlled Environments, July 2005

[11]. GAJADHAR, Tswana; LARA, Alicia; SEALY, Patricia and ADESIYUN, Abiodun A.. Microbial contamination of disinfectants and antiseptics in four major hospitals in Trinidad. Rev Panam Salud Publica [online]. 2003, vol.14, n.3, pp. 194 